\title{
Highly selective enrichment of aflatoxin B1 from edible oil using polydopamine-modified magnetic nanomaterials
}

\author{
Jianguo SHENG ${ }^{1 *}$, Jingjing ZUO ${ }^{1 *}$, Kejie LIU ${ }^{1 *}$, Lei MA ${ }^{1 *}$, Chao LI ${ }^{1 *}$, Yaqi $\mathrm{LI}^{1 *}$, Dezhao KONG ${ }^{1 * \star}$ (i)
}

\begin{abstract}
Aflatoxin $\mathrm{B}_{1}\left(\mathrm{AFB}_{1}\right)$ is a highly toxic mycotoxin that enters the human body through the food chain and poses a serious threat to human health. In this paper, polydopamine (PDA)-coated $\mathrm{Fe}_{3} \mathrm{O}_{4}$ magnetic nanoparticles $\left(\mathrm{Fe}_{3} \mathrm{O}_{4} @ \mathrm{PDA} \mathrm{MNPs}\right)$ were prepared by the co-precipitation method to enrich aflatoxin from edible oil. Transmission electron microscopy (TEM), Fourier transform infrared spectroscopy, X-ray photoelectron spectroscopy, and vibrating sample magnetometer were used to characterize the $\mathrm{Fe}_{3} \mathrm{O}_{4} @ P D A$ MNPs. Using the obtained $\mathrm{Fe}_{3} \mathrm{O}_{4} @ P D A$ MNPs as an adsorbent, a simple method for enriching $\mathrm{AFB}_{1}$ from samples by magnetic solid phase extraction (MSPE) combined with fluorescence rapid detection was developed. The effects of the ratio of $\mathrm{Fe}_{3} \mathrm{O}_{4}$ MNPs to PDA, adsorption dosage, sample volume, adsorption time, and elution time on enrichment of $\mathrm{AFB}_{1}$ were investigated to determine the optimal experimental conditions. This method has good intraday and daytime precision.
\end{abstract}

Keywords: polydopamine; magnetic nanoparticles; selective enrichment; Aflatoxin $\mathrm{B}_{1}$.

Practical Application: Polydopamine was used for $\mathrm{Fe}_{3} \mathrm{O}_{4}$ magnetic nanoparticles coating by the co-precipitation method. This material can be used for selective enrichment of $\mathrm{AFB}_{1}$ in edible oil with high enrichment factor and has good intraday precision and daytime precision.

\section{Introduction}

Mycotoxins are toxic secondary metabolites produced by a variety of molds that can cause serious harm to human health by contaminating various foods and animal feeds (Abia et al., 2013). In recent years, aflatoxins have become one of the most important and highly toxic groups of mycotoxins; they have been frequently detected in agriculture, attracting global attention (Pietri et al., 2016). Among the aflatoxins, aflatoxin $B_{1}\left(A_{F B}\right)$ is the most toxic, and was listed as the first class of carcinogens by the International Agency for Research on Cancer (Lee et al., 2015). It is primarily produced by Aspergillus flavus and Aspergillus parasiticus. Many studies have shown that $\mathrm{AFB}_{1}$ is genotoxic, carcinogenic, embryotoxic, teratogenic, and immunotoxic, (Kew, 2013). $\mathrm{AFB}_{1}$ is widely distributed in nature and food, especially in peanuts, corn, rice, sorghum, milk, and oil (Li et al., 2018). Edible oil contaminated by $\mathrm{AFB}_{1}$ has been widely distributed throughout the human population. This kind of pollution is difficult to remove and seriously threatens human health and safety (Dai et al., 2017). Therefore, a safe and effective strategy is need to detect and degrade $\mathrm{AFB}_{1}$ in food.

The sample pretreatment methods currently applied to mycotoxins mainly include immunoaffinity chromatography purification (Li et al., 2006), dispersion liquid microextraction (Afzali et al., 2012), solid phase extraction (Zhao et al., 2017), solid phase microextraction (Khayoon et al., 2014), matrix solid phase dispersion extraction (Rubert et al., 2010), and QuEChER technology (Zhou et al., 2016; Koesukwiwat et al., 2014), among others. These methods are commonly used to process samples with individual or multiple related mycotoxins, but their operation is often complicated, time-consuming, and costly.
Magnetic solid phase extraction (MSPE) is a new type of sample preparation technology widely used in the detection of organic pollutants (Jiang et al., 2016; Zheng et al., 2014), metal ions (Xiang et al., 2013), and biologically active substances (Xu et al., 2016). Because $\mathrm{Fe}_{3} \mathrm{O}_{4}$ submicron particles coated with polydopamine ( $\left.\mathrm{PDA}, \mathrm{Fe}_{3} \mathrm{O}_{4} @ \mathrm{PDA}\right)$ are magnetic, have a large surface area, strong adsorption capacity, hydrophilicity, and are easily separated, they are considered an ideal adsorption material. In this paper, the magnetic adsorbent $\mathrm{Fe}_{3} \mathrm{O}_{4}$ and its modification were prepared to enrich $\mathrm{AFB}_{1}$ in samples using the MSPE method under the auxiliary conditions of oscillation or ultrasound. The magnetic adsorbent containing $\mathrm{AFB}_{1}$ was separated from the sample matrix by an external magnetic field. $\mathrm{AFB}_{1}$ eluted from the magnetic adsorbent was rapidly detected by fluorescent immunization. MSPE technology is much faster to use than traditional solid phase extraction technology in column or filtration operations. Moreover, when the contact area of the magnetic adsorbent and the target analyte in the extraction process is sufficiently large, the phase transfer of the target analyte can be completed quickly with a high extraction efficiency.

\section{Materials and Methods}

\subsection{Materials and reagents}

Ferric chloride hexahydrate $\left(\mathrm{FeCl}_{3} \cdot 6 \mathrm{H}_{2} \mathrm{O}\right)$, ammonium acetate $\left(\mathrm{NH}_{4} \mathrm{Ac}\right)$, sodium citrate, ethylene glycol (EG), ethyl alcohol $(\mathrm{EtOH})$, acetonitrile $(\mathrm{ACN})$, hydrochloric acid $(\mathrm{HCl})$, sodium hydroxide $(\mathrm{NaOH})$, methyl alcohol $(\mathrm{MeOH})$, and 
dichloromethane $\left(\mathrm{CH}_{2} \mathrm{Cl}_{2}\right)$ were of analytical grade or higher. The experimental water was deuterium-depleted water (DDW). Nitrogen was obtained from Pujiang Special Gas Co., Ltd. (Shanghai, China)

\section{Apparatus}

A magnetic force heating mixer was obtained from Changzhou Putian Instrument Manufacturing Co. Ltd. (Changzhou, Wuxi, China). A KQ-200KDB ultrasonic cleaner was obtained from Kunshan Ultrasonic Instrument Co. Ltd.. An S-4800IIFESE scanning electron microscope was obtained from High-Technologies Corporation (Japan). A Tecnai 12 transmission electron microscope was obtained from Philips Company (Netherlands). An IS410 Fourier transform infrared spectrometer was obtained from ThermoFisher. A PPMS-9 MPMS-XL vibrating sample magnetometer was obtained from Quantum Design. An ESCALAB 25 X-ray photoelectron spectroscope was obtained from Thermo Scientific (USA). A DHG-9101-1S electrothermal blowing dry box was obtained from Changzhou Putian Instrument Manufacturing Co. Ltd. (Changzhou, Wuxi, China). An FD-100 fluorescent quantitative immunoanalyzer was obtained from Shanghai Feice Biotechnology Co. Ltd..

\subsection{Preparation of $\mathrm{Fe}_{3} \mathrm{O}_{4} @ P D A M N P s$}

First, $1.350 \mathrm{~g}$ of $\mathrm{FeCl}_{3} \cdot 6 \mathrm{H}_{2} \mathrm{O}, 3.854 \mathrm{~g}$ of $\mathrm{NH}_{4} \mathrm{Ac}$ and $0.4 \mathrm{~g}$ of sodium citrate were dissolved in $70 \mathrm{~mL}$ of $\mathrm{EG}$, then stirred at $25^{\circ} \mathrm{C}$ for $10 \mathrm{~min}$ to dissolve the reactants completely. The mixed solution was heated for $1 \mathrm{~h}$ at $170^{\circ} \mathrm{C}$, and then placed in a stainless-steel high-pressure autoclave equipped with a polytetrafluoroethylene lining. The reaction kettle was sealed at $200^{\circ} \mathrm{C}$ for $12 \mathrm{~h}$, and then cooled to room temperature. Magnetic products were separated and collected by magnets, washed with $\mathrm{EtOH}$ and DDW three times, and then dried in a vacuum dryer at $60{ }^{\circ} \mathrm{C}$ for $24 \mathrm{~h}$ to obtain pure $\mathrm{Fe}_{3} \mathrm{O}_{4}$ MNPs.

The synthesized $\mathrm{Fe}_{3} \mathrm{O}_{4}$ MNPs and dopamine hydrochloride were dissolved in Tris- $\mathrm{HCl}(\mathrm{pH}=8.5)$ solution in a certain proportion, and mechanically stirred at room temperature for $24 \mathrm{~h}$. Then the product was separated and collected by magnets and washed with $\mathrm{EtOH}$ and DDW three times. Finally, it was dried in a vacuum dryer at $60^{\circ} \mathrm{C}$ for $24 \mathrm{~h}$ to obtain a pure core-shell structured $\mathrm{Fe}_{3} \mathrm{O}_{4} @ \mathrm{PDA}$ MNPs.

\subsection{Fluorescence rapid detection of $A F B_{1}$}

One milliliter of the $\mathrm{AFB}_{1}$-containing oil sample and the sample extract in a 1:5 ratio were added to a $10-\mathrm{mL}$ centrifuge tube and placed on a shaking incubator for $8 \mathrm{~min}$. After extracting, the tube was centrifuged for $2 \mathrm{~min}$ at $4000 \mathrm{rpm}$. Then $100 \mu \mathrm{L}$ of the supernatant was added to $600 \mu \mathrm{L}$ of the sample dilution solution. After mixing, $100 \mu \mathrm{L}$ sample solution was added to the $\mathrm{AFB}_{1}$ fluorescent quantitative rapid detection reagent strip sample hole by pipette, incubated for $8 \mathrm{~min}$, and then the reagent strip was inserted into the fluorescence reader to determine the concentration of $\mathrm{AFB}_{1}$ in the oil sample.

\subsection{Enrichment and elution of $A F B_{1}$}

After determining the $\mathrm{AFB}_{1}$ concentration, $25 \mathrm{~mL}$ of sample solution containing $3.6 \mu \mathrm{g} / \mathrm{L}$ of $\mathrm{AFB}_{1}$ was transferred into a $100 \mathrm{~mL}$ beaker. Then, $0.03 \mathrm{~g}$ of activated $\mathrm{Fe}_{3} \mathrm{O}_{4} @ \mathrm{PDA}$ MNPs was added, and the suspension was oscillated to facilitate the adsorption of $\mathrm{AFB}_{1}$ onto the surface of the adsorbent. Then, the mixture was placed on a super magnet and magnetically separated into a solution and solid $\mathrm{Fe}_{3} \mathrm{O}_{4} @ \mathrm{PDA}$ MNPs. The concentration of $\mathrm{AFB}_{1}$ in the separated solution was determined, then $2.0 \mathrm{~mL}$ of a mixture of $\mathrm{Me}_{2} \mathrm{CO} / \mathrm{ACN} \mathrm{CH}_{2} \mathrm{Cl}_{2}(1: 1: 2, \mathrm{v} / \mathrm{v} / \mathrm{v})$ was added and the mixture was subjected to ultrasonication for $10 \mathrm{~min}$. After desorption, the eluent was separated by magnetic decantation and evaporated to dryness under nitrogen gas flow at room temperature. The dry residue was dissolved in $2.0 \mathrm{~mL}$ of $0.5 \mathrm{mM}$ Triton X-100 in 15\% (v/v) ACN/water and the solution was oscillated for $5 \mathrm{~min}$. The final solution was evaporated to $300 \mu \mathrm{L}$ under nitrogen and the concentration of $\mathrm{AFB}_{1}$ was determined.

\subsection{Method validation}

Intraday precision was evaluated by spiking samples with three different $\mathrm{AFB}_{1}$ concentrations $(1.8,3.6$, or $7.2 \mu \mathrm{g} / \mathrm{L})$. Five replicates of each concentration were analyzed on the same day to determine the accuracy of the method. For interday precision, samples spiked with the same amount of $\mathrm{AFB}_{1}$ were analyzed on three consecutive days. The precisions were expressed as the percentage relative standard deviation (RSD). The enrichment factor $(\mathrm{EF})$ of the method and recovery was calculated using the following equation:

Recovery $(\%)=($ Measured concentration $/$ Nominal concentration $) \times 100 \%(1)$

$\mathrm{EF}=\mathrm{S}_{\mathrm{s}} / \mathrm{Sel} \times \mathrm{R} \%$

where $S_{s}=$ sample volume, $\mathrm{Sel}=$ elution volume, and $\mathrm{R} \%=$ percent recovery.

\section{Results and discussion}

\subsection{Characterization of MNPs}

\section{Electron microscopy}

In the weakly alkaline solution Tris- $\mathrm{HCl}$, dopamine self-polymerized and adsorbed onto the surface of the $\mathrm{Fe}_{3} \mathrm{O}_{4}$ MNPs. The magnetic nanoparticles $\left(\mathrm{Fe}_{3} \mathrm{O}_{4} @ \mathrm{PDA} \mathrm{MNPs}\right)$ coated with polydopamine were obtained. The shape and size of the $\mathrm{Fe}_{3} \mathrm{O}_{4} \mathrm{MNPs}$ and $\mathrm{Fe}_{3} \mathrm{O}_{4} @$ PDA MNPs were visualized and characterized by TEM and SEM images. As shown in Figure 1a and b, the synthesized magnetic $\mathrm{Fe}_{3} \mathrm{O}_{4}$ MNPs were homogeneous particles that were slightly aggregated and approximately $250 \mathrm{~nm}$ in size. Figure $1 \mathrm{c}$ is the TEM diagram of dopamine-coated $\mathrm{Fe}_{3} \mathrm{O}_{4} @ \mathrm{PDA}$ MNPs. The individual particles were approximately $350 \mathrm{~nm}$. The polymer coating formed by polydopamine adsorbed onto the surface of $\mathrm{Fe}_{3} \mathrm{O}_{4} \mathrm{MNPs}$ was formed by hydroxyl-iron chemical interaction.

\section{$X$-ray diffraction of MNPs.}

In order to verify the $\mathrm{Fe}_{3} \mathrm{O}_{4} @ P D A$ MNPs were properly prepared in this assay, the crystal structure and phase composition 
of the materials were analyzed by X-ray diffraction. As shown in Figure 2 (top), the characteristic peaks of all samples were consistent with the $\mathrm{Fe}_{3} \mathrm{O}_{4}$ standard card (JCPDS19-0629), and there were obvious diffraction peaks at $2 \theta=18.3^{\circ}, 30.1^{\circ}$, $35.5^{\circ}, 37.1^{\circ}, 43.1^{\circ}, 53.7^{\circ}, 57.6^{\circ}$, and $62.8^{\circ}$, which correspond respectively with (111), (220), (311), (222), (400), (422), (511), and (440) crystal faces, demonstrating that the obtained products all had a spinel structure. After being wrapped with polydopamine, as shown in Figure 2 (bottom), its spectrum remained essentially unchanged, which means that the addition of polydopamine had no effect on the structure. Using the Debye-Scherrer formula (Equation 3), the particle size (D) of the magnetic nanoparticles can be estimated.

$D=K \lambda /(\beta \cos \theta)$

Where: $\mathrm{D}=$ particle diameter of the magnetic nanoparticle magnetic core, $\mathrm{K}=0.89$ (constant), $\lambda=0.154056 \mathrm{~nm}$ (incident wavelength), and $\beta$ is the half-peak width at the strongest peak (311), which is the diffraction angle. In Figure 2, $\beta=0.00137 \mathrm{rad}, 2 \theta=35.5^{\circ}$ at the strongest peak, and the calculated magnetic core particle size is $220.44 \mathrm{~nm}$, which is similar to the average particle diameter of the magnetic core measured by TEM.

The Fourier transform infrared spectra of the prepared $\mathrm{Fe}_{3} \mathrm{O}_{4}$ MNPs and $\mathrm{Fe}_{3} \mathrm{O}_{4} @ P D A$ MNPs are shown in Figure 3a. The absorption peak at $3430 \mathrm{~cm}^{-1}$ is the stretching vibration peak of the $\mathrm{OH}$ functional group, and the corresponding bending vibration peak is at $1623 \mathrm{~cm}^{-1}$. There is a strong absorption band near $575 \mathrm{~cm}^{-1}$, which is the stretching vibration peak of the $\mathrm{Fe}-\mathrm{O}-\mathrm{Fe}$ bond and the characteristic absorption peak of $\mathrm{Fe}_{3} \mathrm{O}_{4}$ (Wei et al., 2010). The PDA spectrum shows a large relative in the area of $1500-1100 \mathrm{~cm}^{-1}$. Absorbance, which is due to the formation of polymers, is primarily attributable to $\mathrm{CO}$ and CN functional groups (Si \& Yang, 2011). The peak at $1507 \mathrm{~cm}^{-1}$ indicates the presence of the N-H bending vibration; at $1435 \mathrm{~cm}^{-1}$ is the $\mathrm{C}-\mathrm{C}$ tensile vibration, and the weaker peak at $1281 \mathrm{~cm}^{-1}$ indicates the presence of $\mathrm{C}-\mathrm{O}$ tensile vibration.

$\mathbf{a}$

b

c

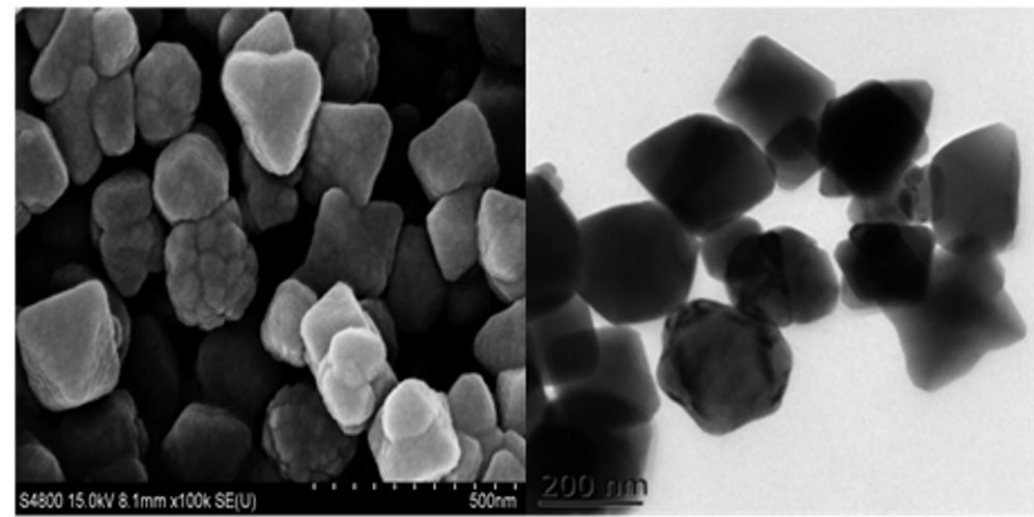

$\underline{200 \mathrm{~nm}}$

Figure 1. (a) SEM of $\mathrm{Fe}_{3} \mathrm{O}_{4}$ MNPs, (b) TEM of $\mathrm{Fe}_{3} \mathrm{O}_{4}$ MNPs, (c) TEM of $\mathrm{Fe}_{3} \mathrm{O}_{4} @ P D A$ MNPs.

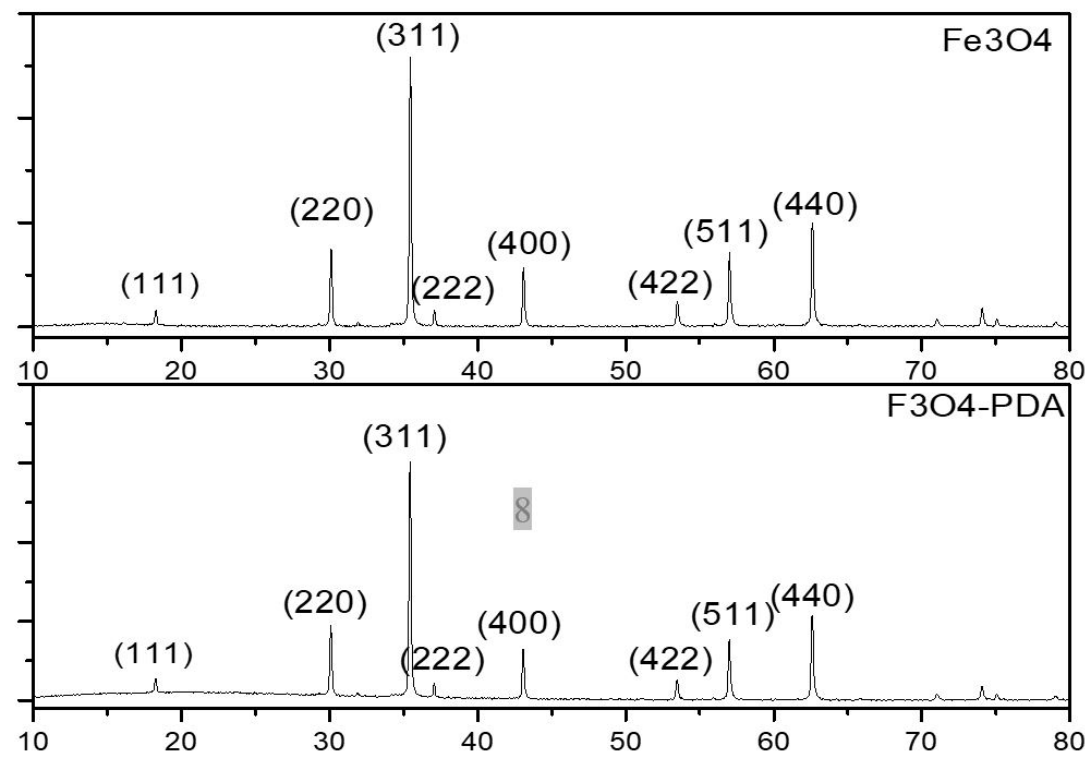

Figure 2. XRD of $\mathrm{Fe}_{3} \mathrm{O}_{4} \mathrm{MNPs}$ (top) and $\mathrm{Fe}_{3} \mathrm{O}_{4} @ P D A$ MNPs (bottom). 
It has been reported that after the surface polymerization of dopamine, some absorption bands in the infrared spectrum are slightly changed (Zeng et al., 2013).

\section{$X$-ray photoelectron spectroscopy of MNPs}

$\mathrm{X}$-ray photoelectron spectroscopy was used to investigate the elemental composition of the surface of magnetic nanomaterials. As shown in Figure 3b, the surface of $\mathrm{Fe}_{3} \mathrm{O}_{4}$ MNPs was mainly composed of $\mathrm{Fe}$ and $\mathrm{O}$ elements. After dopamine modification, the surface of the magnetic nanomaterials also contained $\mathrm{N}$ and $\mathrm{C}$ elements, and the intensity of the Fe element signal peak is significantly weakened. The result indicates that polydopamine was successfully coated onto the surface of $\mathrm{Fe}_{3} \mathrm{O}_{4}$ MNPs (Chen et al., 2018).
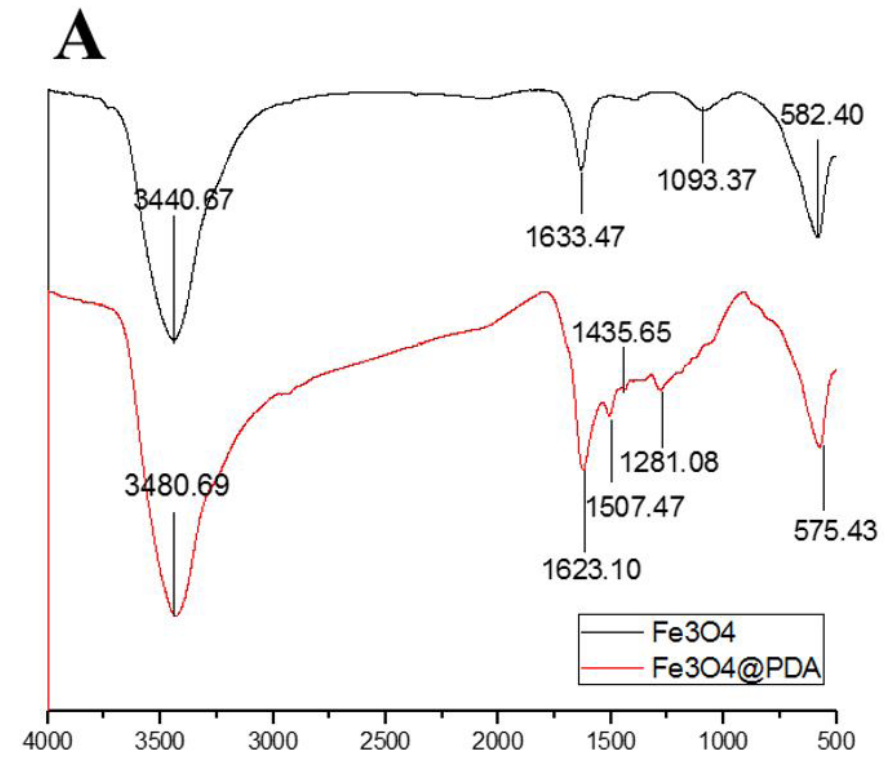

\section{Vibrating sample magnetometer of MNPs}

In order to achieve rapid solid-liquid separation of magnetic nanomaterials from aqueous solution, $\mathrm{Fe}_{3} \mathrm{O}_{4} @$ PDA MNPs must have sufficient magnetic strength. The magnetic properties of $\mathrm{Fe}_{3} \mathrm{O}_{4}$ MNPs and $\mathrm{Fe}_{3} \mathrm{O}_{4} @ \mathrm{PDA}$ MNPs were investigated by vibrating sample magnetometer. The hysteresis loop of $\mathrm{Fe}_{3} \mathrm{O}_{4} @ P D A$ MNPs is shown in Figure 4. The maximum saturation magnetization of $\mathrm{Fe}_{3} \mathrm{O}_{4}$ MNPs and $\mathrm{Fe}_{3} \mathrm{O}_{4} @ P D A$ MNPs was 90 and $45 \mathrm{emu} / \mathrm{g}$, respectively. The coercivity and residual magnetization of the two MNP types were close to zero, which is characterized by paramagnetism. Compared with unmodified $\mathrm{Fe}_{3} \mathrm{O}_{4}$ MNPs, the saturation magnetic strength of dopamine-modified $\mathrm{Fe}_{3} \mathrm{O}_{4} @$ PDA MNPs was significantly weakened due to the non-magnetic polymer coating, but the maximum saturation magnetic strength

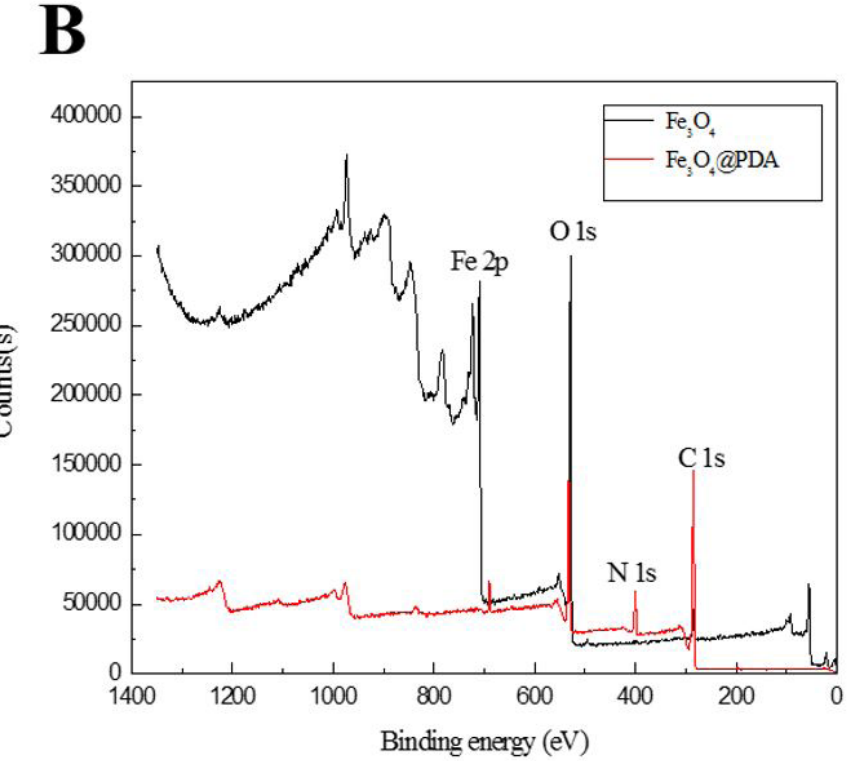

Figure 3. (A) FT-IR of $\mathrm{Fe}_{3} \mathrm{O}_{4}$ MNPs and $\mathrm{Fe}_{3} \mathrm{O}_{4} @ P D A$ MNPs; (B) XPS of $\mathrm{Fe}_{3} \mathrm{O}_{4}$ MNPs and $\mathrm{Fe}_{3} \mathrm{O}_{4} @ P D A$ MNPs.

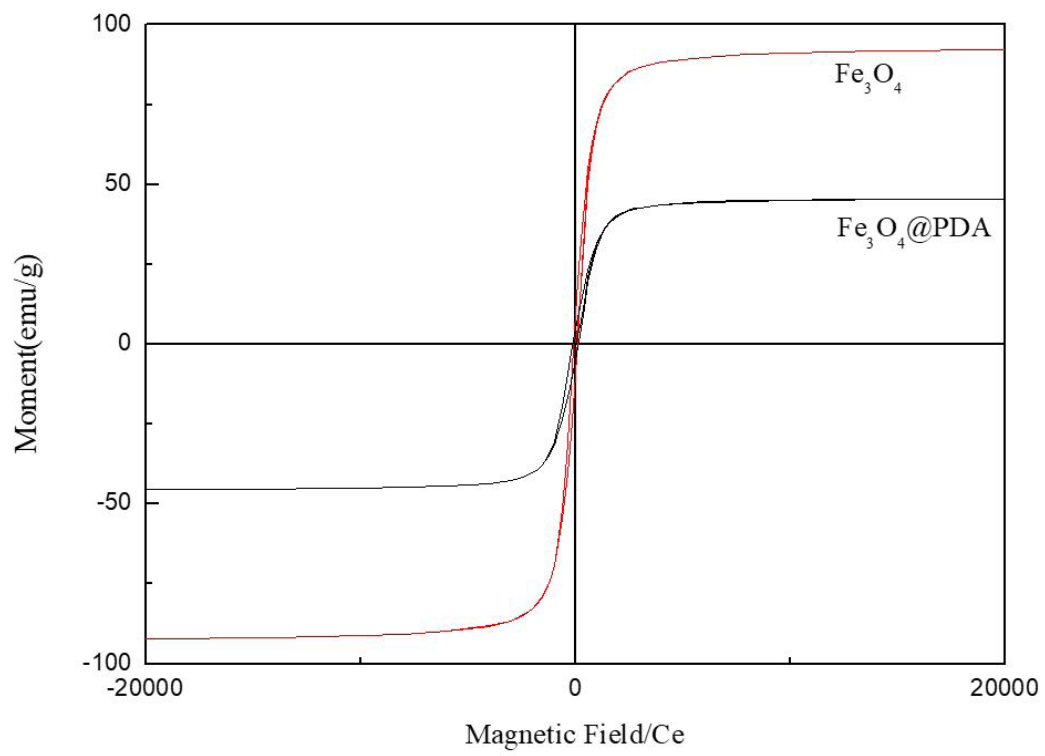

Figure 4. Hysteresis loop spectrum of $\mathrm{Fe}_{3} \mathrm{O}_{4} \mathrm{MNPs}$ and $\mathrm{Fe}_{3} \mathrm{O}_{4} @ P D A$ MNPs. 
of $\mathrm{Fe}_{3} \mathrm{O}_{4} @ \mathrm{PDA}$ MNPs was about 45 emu/g. The magnetic adsorbent can still be used in magnetic adsorption experiments.

It can also be seen from the photograph that the $\mathrm{Fe}_{3} \mathrm{O}_{4} @ P D A$ MNPs were dispersed in water to form a uniform suspension. Under the action of an external magnetic field, the $\mathrm{Fe}_{3} \mathrm{O}_{4} @ P D A$ MNPs were separated from the water and gathered around the magnet, and the solution was transparent. When the applied magnetic field was removed, the $\mathrm{Fe}_{3} \mathrm{O}_{4} @ \mathrm{PDA}$ MNPs were evenly

(a)

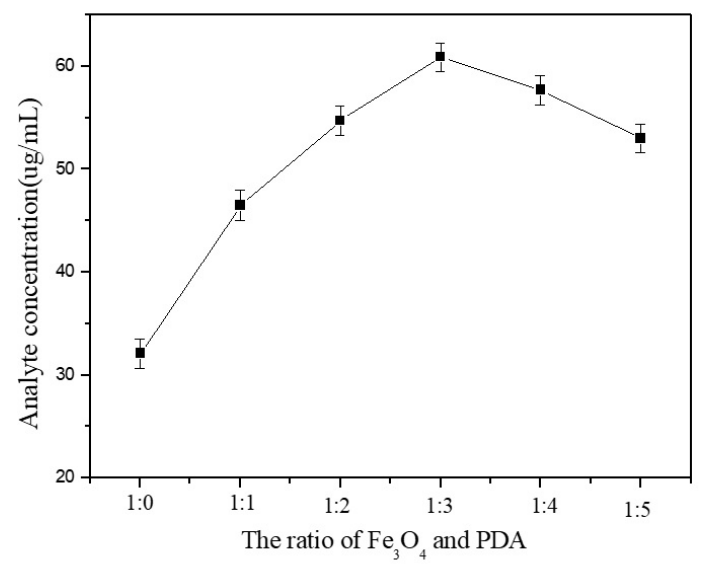

lc

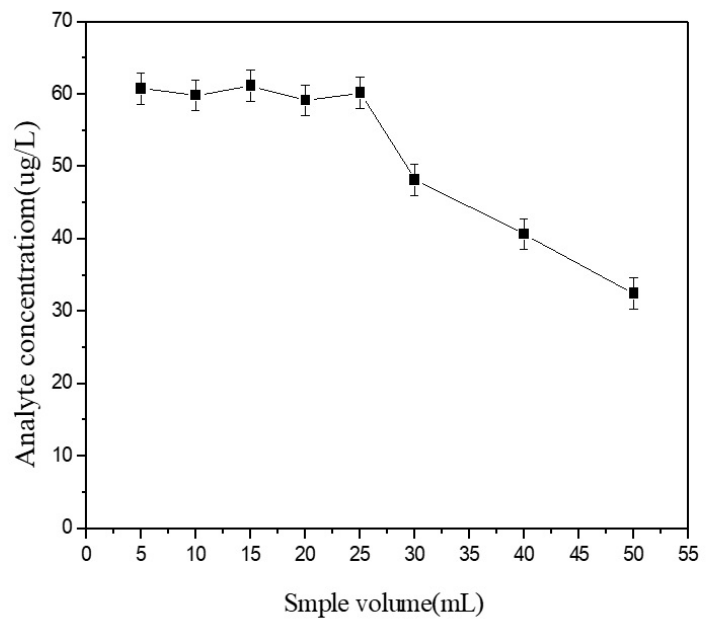

le

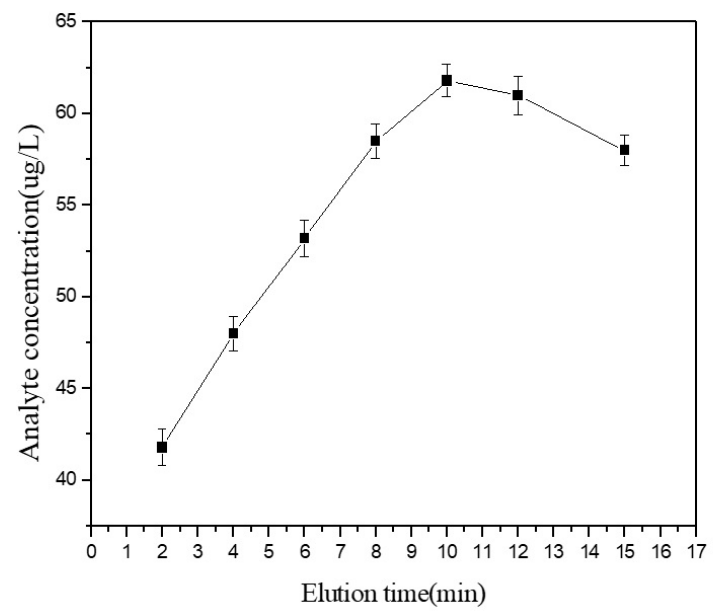

dispersed in the water. This process was repeated to demonstrate that the prepared $\mathrm{Fe}_{3} \mathrm{O}_{4} @ P D A M N P s$ were superparamagnetic.

\subsection{Optimization of the MSPE procedure}

In order to study the effect of different ratios of $\mathrm{Fe}_{3} \mathrm{O}_{4} \mathrm{MNPs}$ and PDA on their $\mathrm{AFB}_{1}$ extraction efficiency, $\mathrm{Fe}_{3} \mathrm{O}_{4} @ \mathrm{PDA}$ MNPs were prepared with different ratios (1:1, 1:2, 1:3, 1:4, 1:5). As shown in Figure 5a, the most effective ratio was 1:3; excessive

(b)

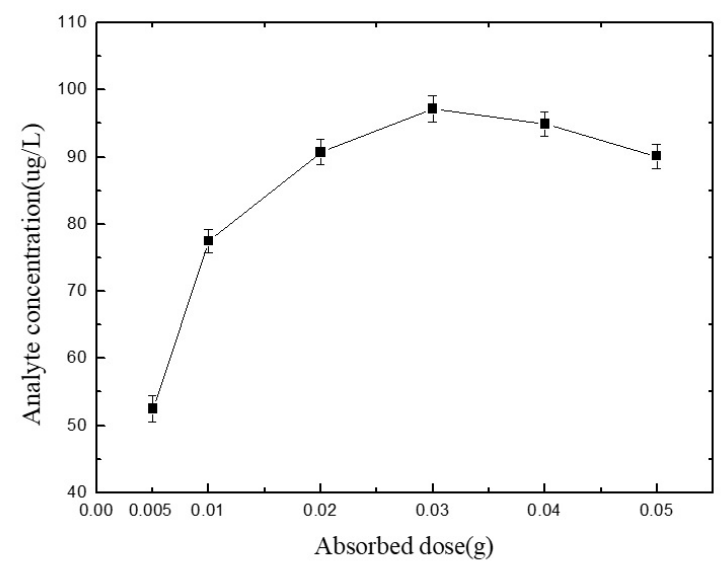

ld

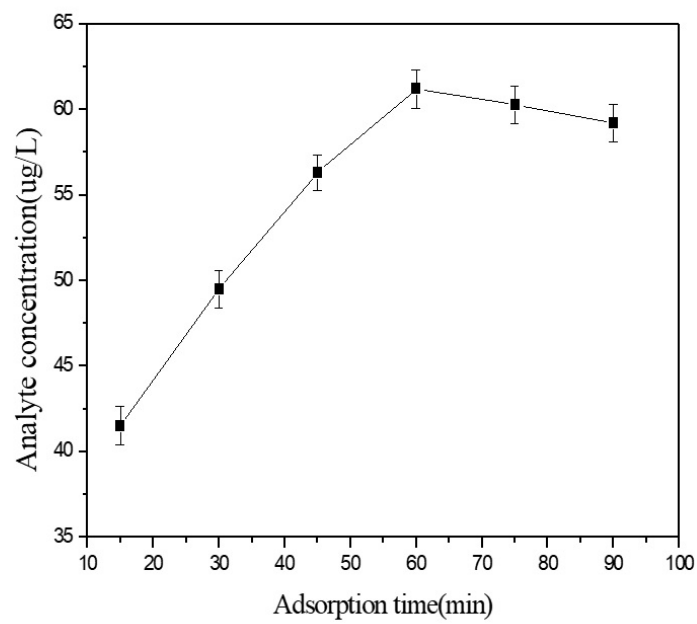

Figure 5. (a) Line chart of the effect of different ratios of $\mathrm{Fe}_{3} \mathrm{O}_{4}$ MNPs and PDA on enrichment; (b) Line chart of the effect of adsorbent dosage on enrichment effect; (c) Histogram of the effect of sample volume on enrichment; (d) Line chart of the effect of adsorption time on enrichment; (e) Line chart of the effect of elution time on enrichment. 
Table 1 Intra-day precision testing.

\begin{tabular}{cccccccc}
\hline Standard concentration $(\mu \mathrm{g} / \mathrm{L})$ & 1 & 2 & 3 & 4 & 5 & RSD $\%$ & Recovery \\
\hline 1.80 & 1.76 & 1.88 & 1.79 & 1.83 & 1.81 & $2.48 \%$ & $101.67 \%$ \\
3.60 & 3.71 & 3.53 & 3.57 & 3.61 & 3.73 & $2.40 \%$ & $100.83 \%$ \\
7.20 & 6.69 & 6.78 & 7.43 & 7.56 & 7.13 & $2.39 \%$ & $98.17 \%$ \\
\hline
\end{tabular}

Table 2 Inter-day precision testing.

\begin{tabular}{ccccc}
\hline Standard concentration $(\mu \mathrm{g} / \mathrm{L})$ & 1 & 2 & 3 & \\
\hline 1.80 & 1.83 & 1.77 & 1.74 & $2.57 \%$ \\
3.60 & 3.72 & 3.64 & 3.61 & $1.56 \%$ \\
7.20 & 7.31 & 7.19 & 6.97 & $2.41 \%$ \\
\hline
\end{tabular}

thickness of the PDA coating reduced the magnetic properties of the material and impact the enrichment effect.

To determine the effect of adsorbent amount on the extraction efficiency of $\mathrm{AFB}_{1}$, different amounts of adsorbent $\mathrm{Fe}_{3} \mathrm{O}_{4} @ \mathrm{PDA}$ MNPs $(0.005,0.01,0.02,0.03,0.04$ and $0.05 \mathrm{~g}$ ) were added to $25 \mathrm{~mL}$ of $3.60 \mu \mathrm{g} / \mathrm{L} \mathrm{AFB}_{1}$ extract. In Figure $5 \mathrm{~b}$, the concentration increased with the amount of the magnetic adsorbent until reaching $0.3 \mathrm{~g}$, and then remained unchanged. The large specific surface area of the nanosorbent may explain the low mass of adsorbent required. Therefore, we chose $0.03 \mathrm{~g}$ as the best adsorbent amount for subsequent experiments.

To evaluate the possibility of enriching low concentrations of $\mathrm{AFB}_{1}$ from large volumes of sample, $5 \mathrm{~mL}$ of $3.60 \mu \mathrm{g} / \mathrm{L} \mathrm{AFB}_{1}$ extract was diluted to $10,15,20,25,30,40$, or $50 \mathrm{~mL}$. Figure $5 \mathrm{c}$ indicates that a quantitative recovery was available at $25 \mathrm{~mL}$. As previously described, the final amount of analyte was $300 \mu \mathrm{L}$. Therefore, the theoretical enrichment factor was 84 , which verifies the feasibility of determining $\mathrm{AFB}_{1}$ at different concentrations.

The remaining experimental conditions were kept unchanged, and the shaking adsorption times tested were $15,30,45,60$, 75 , and $90 \mathrm{~min}$. As show in Figure 5d, adsorption efficiency was maximized when the adsorption time was $60 \mathrm{~min}$ and remained unchanged over longer adsorption times. To shorten the experiment time, the optimal adsorption time was $60 \mathrm{~min}$. Similarly, from Figure 5e, when the elution times tested were 5, 10,15 , and $20 \mathrm{~min}$ in the ultrasound system, the highest analytical effect of the elution time was obtained at $10 \mathrm{~min}$. After the time exceeded $10 \mathrm{~min}$, the elution efficiency began to decrease; thus, 10 min was chosen as the best resolution time.

\subsection{Method validation}

The accuracy of determining the $\mathrm{AFB}_{1}$ concentration of the method was evaluated by preparing standards of different concentrations of $\mathrm{AFB}_{1}$. Table 1 summarizes the results of intraday precision analysis. Table 2 summarizes the results of daytime precision analysis. The RSDs are $2.39 \% \sim 2.48 \%$ and $1.56 \% \sim$ $2.57 \%$, respectively. Intraday and daytime changes indicate that the method has better accuracy. As shown in Table 1, a good recovery rate was in the range of $98.17 \% \sim 101.67 \%$.

\section{Conclusions}

In this study, polydopamine-coated magnetic nanomaterials $\mathrm{Fe}_{3} \mathrm{O}_{4} @ P D A$ MNPs which have a high affinity for aflatoxins were prepared, forming simple and effective magnetic solid particles that can be extracted from large-volume liquid samples. Using $\mathrm{Fe}_{3} \mathrm{O}_{4} @ P D A \mathrm{MNPs}$ as an adsorbent, the microbial aflatoxin $\mathrm{AFB}_{1}$ in edible oil samples was analyzed by fluorescence immunoassay, and the enrichment effect and optimal experimental conditions were determined. The enrichment factor was 84 . The ratio of $\mathrm{Fe}_{3} \mathrm{O}_{4} \mathrm{MNPs}$ to PDA was 1:3, the amount of $\mathrm{Fe}_{3} \mathrm{O}_{4} @ P D A$ MNPs was $0.03 \mathrm{~g}$, the sample volume was $25 \mathrm{~mL}$, the adsorption time was $60 \mathrm{~min}$, and the elution time was $10 \mathrm{~min}$. The method has good intraday precision and daytime precision. The RSDs are $2.39 \% \sim 2.48 \%$ and $1.56 \% \sim 2.57 \%$, respectively, and the recovery rate is in the range of $98.17 \% \sim 101.67 \%$.

\section{Acknowledgements}

This study was supported by Zhenjiang Scientific and Technological Foundation for Social Development (Grant No. SH2017053) and Jiangsu Provincial University students creation (Grant No. 201810289100H). Natural Science Foundation of Jiangsu Province, China (Grant No. BK20180979), The Natural Science Research of Jiangsu Higher Education Institutions of China (Grant no. 18KJB550003), Doctoral Research start-up Funds of Jiangsu university of science and technology (Grant No. 1182931801), and Emerging science and technology innovation team funding of JUST (Grant No. 1182921902)

\section{References}

Abia, W. A., Warth, B., Sulyok, M., Krska, R., Tchana, A. N., Njobeh, P. B., Dutton, M. F., \& Moundipa, P. F (2013). Determination of multi-mycotoxin occurrence in cereals, nuts and their products in Cameroon by liquid chromatography tandem mass spectrometry (LCMS/MS). Food Control, 31(2), 438-453. http://dx.doi.org/10.1016/j. foodcont.2012.10.006.

Afzali, D., Ghanbarian, M., Mostafavi, A., Shamspur, T., \& Ghaseminezhad, S. (2012). A novel method for high preconcentration of ultra trace amounts of B1, B2, G1 and G2 aflatoxins in edible oils by dispersive liquid-liquid microextraction after immunoaffinity column cleanup. Journal of Chromatography. A, 1247, 1247-1258. http://dx.doi. org/10.1016/j.chroma.2012.05.051. PMid:22673813. 
Chen, P., Cao, Z., Wang, S., \& Zhong, H. (2018). In situ nano-silicate functionalized magnetic composites by (poly)dopamine to improve MB removal. Colloids and Surfaces. A, Physicochemical and Engineering Aspects, 552, 89-97. http://dx.doi.org/10.1016/j.colsurfa.2018.05.027.

Dai, Y., Huang, K., Zhang, B., Zhu, L., \& Xu, W. (2017). Aflatoxin B1induced epigenetic alterations: An overview. Food and Chemical Toxicology, 109(Pt 1), 683-689. PMid:28645871.

Jiang, Q., Liu, Q., Chen, Q., Zhao, W., Xiang, G., He, L., Jiang, X., \& Zhang, S. (2016). Dicationic polymeric ionic-liquid-based magnetic material as an adsorbent for the magnetic solid-phase extraction of organophosphate pesticides and polycyclic aromatic hydrocarbons. Journal of Separation Science, 39(16), 3221-3229. http://dx.doi. org/10.1002/jssc.201600267. PMid:27357486.

Kew, M. C. (2013). Aflatoxins as a cause of hepatocellular carcinoma. Journal of Gastrointestinal and Liver Diseases; JGLD, 22(3), 305-310. PMid:24078988.

Khayoon, W. S., Saad, B., Salleh, B., Manaf, N. H., \& Latiff, A. A. (2014). Micro-solid phase extraction with liquid chromatography -tandem mass spectrometry for the determination of aflatoxins in coffee and malt beverage. Food Chemistry, 147, 287-294. http://dx.doi. org/10.1016/j.foodchem.2013.09.049. PMid:24206720.

Koesukwiwat, U., Sanguankaew, K., \& Leepipatpiboon, N. (2014). Evaluation of a modified QuEChERS method for analysis of mycotoxins in rice. Food Chemistry, 153(9), 44-51. http://dx.doi. org/10.1016/j.foodchem.2013.12.029. PMid:24491698.

Lee, J., Her, J. Y., \& Lee, K. G. (2015). Reduction of aflatoxins (B1, B2, G1, and G2) in soybean-based model systems. Food Chemistry, 189, 45-51. http://dx.doi.org/10.1016/j.foodchem.2015.02.013. PMid:26190599.

Li, J., Yu, Y., Tian, M., Wang, H., Wei, F., Li, L., \& Wang, X. (2006). Simultaneous determination of Aflatoxins, Zearalenone and Ochratoxin A in cereal grains by immunoaffinity column and high performance liquid chromatography coupled with post-column photochemical derivatization. Se Pu, 24(6), 581-584. PMid:17288138.

Li, S., Luo, J., Fan, J., Chen, X., \& Wan, Y. (2018). Aflatoxin B1 Removal by multifunctional membrane based on polydopamine intermediate layer. Separation and Purification Technology, 199, 311-319. http:// dx.doi.org/10.1016/j.seppur.2018.02.008.

Pietri, A., Fortunati, P., Mulazzi, A., \& Bertuzzi, T. (2016). Enzymeassisted extraction for the HPLC determination of aflatoxin M1 in cheese. Food Chemistry, 192, 235-241. http://dx.doi.org/10.1016/j. foodchem.2015.07.006. PMid:26304342.

Rubert, J., Soler, C., \& Mañes, J. (2010). Optimization of Matrix SolidPhase Dispersion method for simultaneous extraction of aflatoxins and OTA in cereals and its application to commercial samples. Talanta, 82(2), 560-574. http://dx.doi.org/10.1016/j.talanta.2010.05.008. PMid:20602937.

Si, J., \& Yang, H. (2011). Preparation and characterization of bio-compatible Fe3O4@Polydopamine spheres with core/shell nanostructure. Materials Chemistry and Physics, 128(3), 519-524. http://dx.doi. org/10.1016/j.matchemphys.2011.03.039.

Wei, Q., Zhang, F., Li, J., Li, B. \& Zhao, C. (2010). Oxidant-induced dopamine polymerization for multifunctional coatings. Polymer Chemistry, 1, 1430-1433.

Xiang, G., Li, L., Jiang, X., He, L., \& Fan, L. (2013). Thiol-modified magnetic silica sorbent for the determination of trace mercury in environmental water samples coupled with cold vapor atomic absorption spectrometry. Analytical Letters, 46(4), 11-16. http:// dx.doi.org/10.1080/00032719.2012.726679.

Xu, K., Wang, Y., Li, Y., Lin, Y., Zhang, H., \& Zhou, Y. (2016). A novel poly(deep eutectic solvent)-based magnetic silica composite for solid-phase extraction of trypsin. Analytica Chimica Acta, 946, 64-72. http://dx.doi.org/10.1016/j.aca.2016.10.021. PMid:27823670.

Zeng, T., Zhang, X., Niu, H., Ma, Y., Li, W. \& Cai, Y. (2013). In situ growth of gold nanoparticles onto polydopamine-encapsulated magnetic microspheres for catalytic reduction of nitrobenzene. Applied Catalysis B: Environmental, 134-135:26-33.

Zhao R., An J., Chui W., He L. (2017). Advances in the application of magnetic solid phase extraction in the detection of mycotoxins. Journal of Henan University of Technology (Natural Science Edition), 5:118-126.

Zheng, X., He, L., Duan, Y., Jiang, X., Xiang, G., Zhao, W., \& Zhang, S. (2014). Poly(ionic liquid) immobilized magnetic nanoparticles as new adsorbent for extraction and enrichment of organophosphorus pesticides from tea drinks. Journal of Chromatography. A, 1358, 39-45. http://dx.doi.org/10.1016/j.chroma.2014.06.078. PMid:25022482.

Zhou, Q., Li, F., Chen, L., \& Jiang, D. (2016). Quantitative analysis of 10 Mycotoxins in wheat flour by ultrahigh performance liquid Chromatography-Tandem mass spectrometry with a modified QuEChERS Strategy. Journal of Food Science, 81(11), 469-483. http:// dx.doi.org/10.1111/1750-3841.13524. PMid:27732757. 